\title{
Treatment of Class II Caries Lesions with Application of Packable and Conventional Resin Composites: Clinical and Experimental Study
}

\author{
Timur V. Melkumyan, PhD, ScD ${ }^{1,2 *}$; Angela D. Dadamova ${ }^{1}$; Surayo Sh. Sheralieva ${ }^{1}$; \\ Nuritdin Kh. Kamilov'; Fatima Yu. Daurova, $\mathrm{PhD}, \mathrm{ScD}^{2}$ \\ ${ }^{I}$ Tashkent State Dental Institute, Tashkent, Uzbekistan \\ ${ }^{2} R U D N$ University, Moscow, Russia
}

\begin{abstract}
Background: The aim of the present study was to compare the efficacy of packable and conventional composites in treatment of patients with class II caries lesions (CIICLs).

Methods and Results: The clinical part of the study was conducted on patients with indications for composite restoration of at least two adjacent CIICCLs. There were 32 patients in whom 72 (36 pairs) teeth with caries pathology were treated. One tooth in every pair was randomly assigned for restoration with Filtek Z250 (Cl-Group 1, n=36) and another one with preheated Filtek-P60 (Cl-Group 2, $\mathrm{n}=36$ ). The mean observation time for composite restorations was $47.1 \pm 13.8$ months. The modified USPHS criteria list was applied for clinical evaluation of the four following clinical parameters, which were used in the study: secondary caries, anatomy form, occlusal contact, and surface texture. The experimental study was conducted on 40 filling samples, which were made of conventional Filtek Z250 (Exp-Group 1, n=20) and packable Filtek P60 (Exp-Group 2, n=20) with the help of a transparent plastic mold. Every experimental group was randomly divided into two subgroups (A and B): polymerized filling samples of ExpSubgroups 1A $(n=10)$ and $2 A(n=10)$ were put into the test right after polymerization; samples of Exp-Subgroups $1 B(n=10)$ and 2B $(n=10)$ were passed through a shear-strength test after exposure to four consecutive cycles of autoclaving. Shear-strength measurements were made in an Ultratest Machine (Ultradent, USA), which was adapted to perform a proper test.

The incidence of secondary caries in both clinical groups (two incidents in Gl-Group 1 and one incident in Cl-Croup 2) was very low, and comparative analysis of obtained results did not reveal any significant difference between them. In relation to criteria of anatomy form, the percentage of alpha level of tooth restorations that were done with packable Filtek P60, was $38.9 \%$. Bravo estimates had 50\% of restored teeth. Tooth restorations with conventional Filtek Z250 had alpha level in 58.3\% and bravo in $41.7 \%$ of cases. Occlusal contact and surface texture, the efficacy of CIICL management was better in teeth that had been treated with packable composite. Analysis of experimental findings revealed that the mean value of shear strength for Filtek P60 filling samples, which were tested immediately after polymerization, was lower than the same parameter for Filtek Z250 on $20.5 \%(P<0.01)$. In addition, it was established that the studied parameter for filling samples of Filtek Z250 had decreased by 1.4 times $(28.1 \%)$ after cycles of autoclaving $(P<0.05)$. A similar tendency was observed for Filtek-P60 too, but only $10.2 \%$ showed a decrease in value $(P<0.05)$.

Conclusions: Based on obtained clinical findings it can be concluded that treatment of CIICLs with application of packable

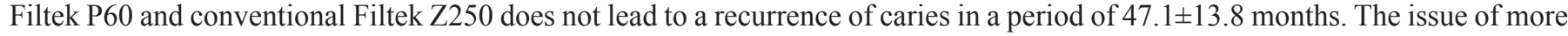
frequent chipping of composite restorations that were made of packable Filtek P60, but not of conventional Filtek Z250, could be of clinical value in treatment planning of patients with excessive occlusal load and tooth wear. In addition, it was clinically noticed that tooth composite restorations made of packable Filtek P60 had values of surface texture that were close to alpha level. (International Journal of Biomedicine. 2020;10(1):66-69.)
\end{abstract}

Key Words: class II caries lesions • packable and conventional composites $\bullet$ shear strength

\section{Introduction}

Since the moment of their appearance on the market, dental composites have had narrow indications for application and are usually used for restoration of anterior teeth. However, during the last several decades, resin restoratives took one of leading places among the materials with indications for direct and indirect restoration of posterior teeth. ${ }^{(1-3)}$

*Corresponding author: Prof. Timur V. Melkumyan, PhD, ScD. Tashkent State Dental Institute, Tashkent, Uzbekistan. E-mail:t.dadamov@gmail.com 
Present achievements in diversifying applications of resin composite filling material could mostly be attributed to the rapidly growing new technologies, directed toward the synthesis of durable, high molecular weight, polymeric matrices with low polymerization shrinkage and stress, which were loaded with nanoparticles in different organic and inorganic ratios. ${ }^{(4-7)}$

Nowadays, the application of dental resins can meet the needs of an enormous variety of clinical situations that require a low invasive approach to the treatment of caries lesions. However, management of patients with indications for direct restoration of class II cavities with composite materials still may be a challenge for dentists, and the invention of packable composites could be of great assistance to them. ${ }^{(8,9)}$

Silver amalgam was the basic material of choice for direct restoration of class I and II cavities for a prolonged period of time. The longevity of this type of restoration was about 20 years, which was due to the long-lasting marginal seal, appropriate wear resistance and cariostatic behavior. ${ }^{(10,11)}$

However, the presence of probable mercury toxicity, tarnish, stains and color of silver amalgam were the main reasons for the application of alternative packable composites that had manipulability and consistency close to silver amalgam, but without any of the abovementioned drawbacks. ${ }^{(12-14)}$

In accordance with their definition, packable composites are hybrid resin restoratives designed for use in posterior dentition, where a stiffer consistency facilitates condensation during cavity filling and restoration. It is noteworthy that the increased stiffness of packable resins is due to the high filler load with particle sizes measured from nanometers to micrometers. ${ }^{(15)}$ Packable composite materials, which are often called condensable, have one substantial advantage over conventional hybrids - they are not sticky. Absence of the tendency to stick to dental instruments allows placing and shaping this type of resin in an unstressful manner during restoration of posterior teeth. However, there are a few other differences between conventional materials and packable composites, which may not be in favor of the latter. ${ }^{(16,17)}$

The results of several studies showed that highly filled composites have better wear resistance and flexural strength than resins with lower filler content. ${ }^{(18,19)}$ On the contrary, the data obtained from other studies indicated that values of the wear resistance and strength of packable resins were the same as for conventional composites, and sometimes they were even worse. ${ }^{(20,21)}$

Previously, a group of researchers stated that in dental composites an inorganic filler part must not exceed $70 \%$ by volume because of technical difficulties and poor handling characteristics. Increased viscosity of resin composites may be of help with respect to low stickiness while inserting filling material, and may cause a problem during the time it is adapting to cavity walls. ${ }^{(22)}$ Many of the abovementioned facts may explain why the prevalence of conventional composites with lower inorganic content and viscosity in posterior teeth is still high.

Therefore, because there is no solid opinion on whether to use a resin material with high filler content or a universal composite, the aim of the present study was to compare the efficacy of packable and conventional composites in treatment of patients with class II caries lesions (CIICLs).

\section{Material and Methods}

The clinical part of the study was conducted on patients with indications for composite restoration of at least two adjacent class II carious cavities. There were 32 patients in whom 72 (36 pairs) teeth with caries pathology were treated.

Patients were treated by one dentist. One tooth in every pair was randomly assigned for restoration with Filtek Z250 (Cl-Group 1, $\mathrm{n}=36$ ) and another one with preheated Filtek-P60 (Cl-Group 2, n=36). The packable Filtek-P60 was preheated to facilitate easy material adaptation to prepared cavity walls.

Basic inclusion criteria into the study were: 1) similar periodontal status and mobility of adjacent teeth with CIICL; 2) similar periodontal status and mobility of antagonist teeth, which should be sound. Presence of satisfactory porcelain or metal restorations on antagonist teeth was not a contraindication for inclusion into the study. The mean observation time for composite restorations was $47.1 \pm 13.8$ months.

Considering that there are only three shades in a restorative system of Filtek-P60 and that in a posterior region of the mouth there is not a high demand for color matching or excessive esthetics, and a reasonable priority of function, the modified USPHS criteria list (Table 1) was applied for clinical evaluation of the four following clinical parameters, which were used in the study: secondary caries, anatomy form, occlusal contact, and surface texture. In order to make an interpretation of final results more informative, every character rating was expressed in a proper conventional unit (CU).

Table 1.

Modified USPHS criteria used for clinical evaluation

\begin{tabular}{|c|c|c|}
\hline Category & Rating, CU & Description \\
\hline $\begin{array}{l}\text { Secondary } \\
\text { caries }\end{array}$ & $\begin{array}{l}\text { alpha (2) } \\
\text { bravo (1) }\end{array}$ & $\begin{array}{l}\text { No caries present } \\
\text { Caries present }\end{array}$ \\
\hline $\begin{array}{l}\text { Occlusal } \\
\text { contact }\end{array}$ & $\begin{array}{l}\text { alpha (3) } \\
\text { bravo (2) } \\
\text { charlie (1) }\end{array}$ & $\begin{array}{l}\text { Normal } \\
\text { Slight } \\
\text { No contact }\end{array}$ \\
\hline $\begin{array}{l}\text { Anatomy } \\
\text { form }\end{array}$ & $\begin{array}{l}\text { alpha (3) } \\
\text { bravo (2) } \\
\text { charlie (1) }\end{array}$ & $\begin{array}{l}\text { No presence of a material chipping } \\
\text { Slight loss of a material, dentin or } \\
\text { base are not exposed } \\
\text { Sufficient loss of a material with } \\
\text { dentin or base exposure }\end{array}$ \\
\hline $\begin{array}{l}\text { Surface } \\
\text { texture }\end{array}$ & $\begin{array}{l}\text { alpha }(3) \\
\text { bravo }(2) \\
\text { charlie (1) }\end{array}$ & $\begin{array}{l}\text { Polished surface of a composite } \\
\text { restoration } \\
\text { Slightly pitted surface of a composite } \\
\text { restoration, possible to refinish } \\
\text { Deeply pitted surface of a composite } \\
\text { restoration, not possible to refinish }\end{array}$ \\
\hline
\end{tabular}

The experimental study was conducted on 40 filling samples, which were made of conventional Filtek Z250 (Exp-Group 1, n=20) and packable Filtek P60 (Exp-Group $2, \mathrm{n}=20$ ) with the help of a transparent plastic mold. Every 
sample was of a standardized cylindrical shape with a mean diameter of $2.46 \pm 0.03 \mathrm{~mm}$ and length of $8.14 \pm 0.12 \mathrm{~mm}$. Light polymerization was initiated with application of Blue Phase iG20 (Ivoclar) in a "High" mode with $40 \mathrm{sec}$ exposure time for every sample in a similar manner.

Every experimental group was randomly divided into two subgroups (A and B): polymerized filling samples of Exp-Subgroups $1 \mathrm{~A}(\mathrm{n}=10)$ and $2 \mathrm{~A}(\mathrm{n}=10)$ were put into the test right after polymerization; samples of Exp-Subgroups 1B $(\mathrm{n}=10)$ and $2 \mathrm{~B}(\mathrm{n}=10)$ were passed through a shear-strength test after exposure to four consecutive cycles of autoclaving.

Shear-strength measurements were made in an Ultratest Machine (Ultradent, USA), which was adapted to perform a proper test. Values were registered in pounds (lb).

Statistical analysis was performed using StatSoft Statistica v7.0. The mean (M) and standard deviation (SD) were calculated. The Mann-Whitney U Test was used to compare the differences between the two groups. A probability value of $P<0.05$ was considered statistically significant.

\section{Results and Discussion}

In the present study, the mean observation time to assess the quality of treatment of CIICLs with application of Filtek Z250 and Filtek P60 was about four years (Table 2). Within this time period, the incidence of secondary caries in both clinical groups (two incidents in Gl-Group 1 and one incident in $\mathrm{Cl}$ Croup 2) was very low, and comparative analysis of obtained results did not reveal any significant difference between them.

\section{Table 2.}

Treatment efficacy of CIICL and clinical appearance of composite restorations

\begin{tabular}{|c|c|c|c|c|c|}
\hline & $\begin{array}{c}\text { Criterion } \\
\text { of anatomy } \\
\text { form (CU) }\end{array}$ & $\begin{array}{l}\text { Criterion of } \\
\text { secondary } \\
\text { caries (CU) }\end{array}$ & $\begin{array}{l}\text { Observation } \\
\text { time, } \\
\text { (mos) }\end{array}$ & $\begin{array}{l}\text { Criterion of oc } \\
\text { clusal contact } \\
\text { (CU) }\end{array}$ & $\begin{array}{c}\text { Criterion of } \\
\text { surface } \\
\text { texture (CU) }\end{array}$ \\
\hline 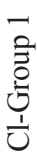 & $2.58 \pm 0.5$ & $1.89 \pm 0.32$ & $47.1 \pm 13.8$ & $2.36 \pm 0.72$ & $2.39 \pm 0.6$ \\
\hline 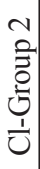 & $2.28 \pm 0.66$ & $1.97 \pm 0.16$ & $47.1 \pm 13.8$ & $2.69 \pm 0.62$ & $2.8 \pm 0.4$ \\
\hline$P$ & $<0.05$ & $>0.05$ & - & $<0.05$ & $<0.01$ \\
\hline
\end{tabular}

However, in relation to criteria of anatomy form, in occlusal contact and surface texture some differences were detected. Thus, the anatomy of composite restorations in ClGroups 1 and 2 had deteriorated on $14 \%$ and $24 \%$, respectively. In addition, there was a statistically significant difference between them $(P<0.05)$, which could be explained by a noticeable predisposition of Filtek-P60 material to chipping.

Therefore, in relation to parameters of anatomy form, the percentage of alpha level of tooth restorations that were done with packable material, was $38.9 \%$. Bravo estimates had $50 \%$ of restored teeth. In the same time, tooth restorations, which were of conventional Filtek Z250, had alpha level in 58.3\% and bravo in $41.7 \%$ of cases.

Taking into account parameters of occlusal contact and surface texture, the efficacy of CIICL management was better in teeth that had been treated with a packable composite.

Analysis of experimental findings revealed (Table 3) that the mean value of shear strength for Filtek P60 filling samples, which were tested immediately after polymerization, was lower than the same parameter for Filtek Z250 on $20.5 \%$ $(P<0.01)$. In addition, it was established that the studied parameter for filling samples of Filtek Z250 had decreased by 1.4 times $(28.1 \%)$ after cycles of autoclaving $(P<0.05)$. A similar tendency was observed for Filtek P60 too, but only $10.2 \%$ showed a decrease in value $(P<0.05)$.

Table 3.

Shear strength of cured resin composites before and after cycles of autoclaving

\begin{tabular}{|l|c|c|c|}
\hline \multicolumn{1}{|c|}{ Subgroups } & $\begin{array}{c}\text { Exp-Group 1 } \\
(\mathrm{lb})\end{array}$ & $\begin{array}{c}\text { Exp-Group 2 } \\
(\mathrm{lb})\end{array}$ & $P$ \\
\hline A $(\mathrm{n}=10)$ & $85.9 \pm 15.1$ & $68.3 \pm 11.2$ & $<0.01$ \\
\hline$P$ & $<0.01$ & $<0.05$ & \\
\hline B $(\mathrm{n}=10)$ & $61.8 \pm 14.5$ & $61.3 \pm 15.2$ & $>0.05$ \\
\hline
\end{tabular}

It is noteworthy, that the difference between mean values of shear-strength findings for packable Filtek P60 and conventional Filtek Z250, which were obtained after an impact of four consecutive cycles of autoclaving, was not of any statistical significance.

The efficacy of CIICL management is strongly materialdependent, since a proper longevity and function of used restorations are the prerequisites of long-term tooth vitality and the healthy status of surrounding periodontal tissues.

Resin composites have been recognized by the dental community as materials of choice because of tooth color esthetics and ease of application. However, durability and wear resistance of this type of restoration remains under question.

Performance of particular laboratory tests and specially designed clinical studies might shed a light on probable clinical behavior of the restoratives that are used. Thus, in the present study it was revealed that lower shear-strength values for filling samples made of Filtek P60 packable composite might explain the chipping of proper restoration in a patient's mouth.

At the same time, it was found that more pronounced degradation of the organic matrix of Filtek Z250 samples in vitro was a reasonable issue of poor surface texture and occlusal contact on this type of tooth restoration in vivo.

Therefore, based on obtained clinical findings it can be concluded that treatment of CIICLs with application of packable Filtek P60 and conventional Filtek Z250 does not lead to a recurrence of caries in a period of $47.1 \pm 13.8$ months.

The issue of more frequent chipping of composite restorations that were made of packable Filtek P60, but not of conventional Filtek Z250, could be of clinical value in 
treatment planning of patients with excessive occlusal load and tooth wear. In addition, it was clinically noticed that tooth composite restorations made of packable Filtek P60 had values of surface texture that were close to alpha level.

\section{Competing Interests} interests.

The authors declare that they have no competing

\section{References}

1. Lyons K; Ministry of Health. Direct placement restorative materials for use in posterior teeth: the current options. N Z Dent J. 2003;99(1):10-5.

2. Qvist V, Qvist J, Mjor IA. Placement and longevity of tooth-colored restorations in Denmark. Acta Odontol Scand. 1990;48(5):305-11.

3. Sunnegårdh-Grönberg K, van Dijken JW, Funegård U, Lindberg A, Nilsson M. Selection of dental materials and longevity of replaced restorations in Public Dental Health clinics in northern Sweden. J Dent. 2009 Sep;37(9):673-8. doi: 10.1016/j.jdent.2009.04.010.

4. Wakefield CW, Kofford KR. Advances in restorative materials. Dent Clin North Am. 2001;45(1):7-29.

5. Shortall AC, Uctasli S, Marquis PM. Fracture resistance of anterior, posterior and universal light activated composite restoratives. Oper Dent. 2001;26(1):87-96.

6. Manhart J, Kunzelmann KH, Chen HY, Hickel R. Mechanical properties of new composite restorative materials. J Biomed 1 Mate Res. 2000;53(4):353-61.

7. Wang K, Yin R, Nie J, Yu Q. Synthesis and characterization of a novel dimethacrylate based on adamantine as possible dental resins. Mater Sci Eng. 2012; C32:1141-1145

8. Elderton RJ. Restorations without conventional cavity preparations. Int Dent J. 1988;38(2):112-8.

9. Suzuki S. Does the wear resistance of packable composite equal that of dental amalgam? J Esthet Restor Dent. 2004;16(6):355-65; discussion 365-7.

10. Qvist J, Qvist V, Mjor IA. Placement and longevity of amalgam restorations in Denmark. Acta Odontol Scand.
1990;48(5):297-303.

11. Opdam NJ, Bronkhorst EM, Roeters JM, Loomans BA. A retrospective clinical study on longevity of posterior composite and amalgam restorations. Dent Mater. 2007;23(1):2-8.

12. Hahn LJ, Kloiber R, Leininger RW, Vimy MJ, Lorscheider FL. Whole-body imaging of the distribution of mercury released from dental fillings into monkey tissues. FASEB J. 1990;4(14):3256-60.

13. Brownawell AM, Berent S, Brent RL, Bruckner JV, Doull $\mathrm{J}$, Gershwin EM, et al. The potential adverse health effects of dental amalgam. Toxicol Rev. 2005;24(1):1-10.

14. Rathore M, Singh A, Pant VA. The dental amalgam toxicity fear: a myth or actuality. Toxicol Int. 2012;19(2):818. doi: 10.4103/0971-6580.97191.

15. Loomans BA, Opdam NJ, Roeters JF, Bronkhorst EM, Plasschaert AJ. Influence of composite resin consistency and placement technique on proximal contact tightness of Class II restorations. J Adhes Dent. 2006;8(5):305-10.

16. de Souza FB, Guimaraes RP, Silva CH. A clinical evaluation of packable and microhybrid resin composite restorations: one-year report. Quintessence Int. 2005;36(1):41. 17. Cobb DS, MacGregor KM, Vargas MA, Denehy GE The physical properties of packable and conventional posterior resin-based composites: a comparison. J Am Dent Assoc. 2000 Nov; 131(11):1610-5.

18. Clelland NL, Pagnotto MP, Kerby RE, Seghi RR. Relative wear of flowable and highly filled composite. J Prosthet Dent. $2005 \mathrm{Feb} ; 93(2): 153-7$.

19. Knobloch L, Kerby RE, Clelland N, Lee J. Hardness and degree of conversion of posterior packable composites. Oper Dent. 2004 Nov-Dec;29(6):642-9.

20. Mair LH. Ten-year clinical assessment of three posterior resin composites and two amalgams. Quintessence Int. 1998;29(8):483-90.

21. Turssi CP, Faraoni-Romano JJ, de Menezes M, Serra MC. Comparative study of the wear behavior of composites for posterior restorations. J Mater Sci Mater Med. 2007;18(1):143147.

22. Willems G, Lambrechts P, Braem M, Celis JP, Vanherle G. A classification of dental composites according to their morphological and mechanical characteristics. Dent Mater. 1992;8(5):310-9. 